\title{
STUDY OF CONDITIONS OF GULLY FORMATION IN MOUNTAIN REGIONS OF SOUTH-EAST KAZAKHSTAN WITH USE OF GIS-TECHNOLOGIES
}

\author{
Yerkebulan KHALYKOV ${ }^{1,2}$, Yuisya LYY $^{2}$, Edil SARYBAEV ${ }^{3 *}$, Maulen TOGYS ${ }^{2}$, \\ Saule UKSUKBAYEVA ${ }^{2}$, Zhanerke SHARAPKHANOVA ${ }^{2}$ \\ ${ }^{1}$ Satbayev University, Almaty, Kazakhstan \\ ${ }^{2}$ Institute of Geography and Water Security, Almaty, Kazakhstan \\ ${ }^{3}$ Al-Farabi Kazakh National University, Almaty, Kazakhstan
}

Received 19 February 2020; accepted 14 June 2021

\begin{abstract}
In the article the results of field and laboratory researches of gully erosion in the mountains of Zhetysu Alatau of south-east Kazakhstan are considered. Mountain ridge Malaisary was chosen for study of gully erosion. Malaisary ridge is the western ridge of Zhetysu Alatau mountains in the south-east Kazakhstan. Foothills and plain territories of southeast Kazakhstan are characterized by favorable conditions for the development of erosion processes. There was conducted stationary monitoring (yearly in October from 2013 to 2018) of gully erosion development on the Malaisary ridge from 2013 to 2018. Most of gullies of studied ridge show development in the top part and extend in the width mainly due to fluvial processes. There were studied the natural-anthropogenic factors influencing development of gully erosion; the morphometric characteristic received using the modern devices and satellite images are provided. The determined factors of development of gullies on Malaisary ridge are mechanical substratum composition, atmospheric precipitation (spring runoff, summer rainfalls), steepness and length of the slopes. The received materials allow concluding that gully erosion is the most active factor of the ridge relief transformation. Intensive gully erosion development increases ecological tension of natural-anthropogenic environment in the region. Growth of gully net and its active development deteriorates quality of agricultural lands and create threat to road objects and residential area infrastructure in the region.
\end{abstract}

Keywords: gully erosion, gullies, natural and anthropogenic factors, GIS, Malaisary ridge, Zhetysu Alatau.

\section{Introduction}

The problem of land degradation is a problem of global importance, due to climate change and unadvised farming of the local population. Land degradation processes are presented in all natural zones of Kazakhstan, but are most expressed in the foothill and lowland areas, where significant land areas are used for agricultural production. The choice of the study region is connected to the fact that $21.3 \%$ of the population of the Republic of Kazakhstan lives in southeastern Kazakhstan, and about 30\% of agricultural products are produced there, and due to these factors, the processes of land degradation are going most intensive here, reducing the fertility and productivity of agricultural land. The main reasons of land degradation are secondary salinization, wind and water erosion of soils. Water erosion is one of the leading processes of soil cover degradation on agricultural land. Among the processes of water erosion, the most unfavorable are the processes of gully erosion. The development of ravines is attracting more and more attention from researchers, farmers and various land users. The interest is connected with the growing concern about the increase in the area of cultivated land subjected to gully erosion. Assessment of the dynamics and monitoring of gully erosion in the zone of intensive farming in the south-east of Kazakhstan is relevant due to the lack of reliable data on the development of this type of erosion over the past decades. The modern development of geoinformation technologies and the appearance of high and ultra-high resolution satellite images make it possible to successfully solve the problems of monitoring the processes of gully erosion, the dynamics of ravines, as well as identifying potential lands subjected to gully erosion.

*Corresponding author. E-mail: edilait@mail.ru

Copyright $\odot 2021$ The Author(s). Published by Vilnius Gediminas Technical University

This is an Open Access article distributed under the terms of the Creative Commons Attribution License (http://creativecommons.org/licenses/by/4.0/), which permits unrestricted use, distribution, and reproduction in any medium, provided the original author and source are credited. 
Development of gullies attracts more and more attention of scientists, farmers and different land users. Interest is connected with growing concern about increase of areas of cultivated lands subjected to gully erosion. Gully erosion throughout the history of studying was recognized as the main process of land degradation and in many cases was directly connected with unstable management of land resources (Castillo \& Gómez, 2016). Gullies, by uncontrolled development, considerably affect agriculture, settlements and communications. They represent the main source of alluvium development and change quality of inter valley lands (Li et al., 2017). Gullies development (from initiation till termination) is often could fit the period of one human generation. Gullies belong to most effective and dynamic relief forms of plain regions (Kosov et al., 1989).

Analysis of the condition of the region's land resources shows that the development of gully erosion processes is accelerated as a result of human agricultural activities. To solve the task of the effective and rational use of land as a resource and prevent it from degradation, it is necessary to comprehensively study all the factors causing it, to obtain quantitative data on the dynamics of gully erosion.

Studied territory is located between $44^{\circ} 17^{\prime}-44^{\circ} 20^{\prime}$ Northand $76^{\circ} 45^{\prime}-77^{\circ} 55^{\prime}$ East (Figure 1). Hypsometric region covers altitudes from 570 till $1380 \mathrm{~m}$ a.s.l. Gully forms were studied on the territory of Zhetysu region on Malaisary ridge from 2013 to 2018, where stationary monitoring (yearly in October) was conducted. Key site is located $51.7 \mathrm{~km}$ to the North from Kapshagai town and $1.8 \mathrm{~km}$ to the East from the road Almaty-Bakanas. Choice of key site for studying of grows of top parts of gully was made usingsatellite images from the open sources and topographic maps of the area. One of the characteristics, determining erosion danger of the territory is dynamic linear characteristic of erosive forms. On the key site there was conducted monitoring of linear grows of the top part of gully.

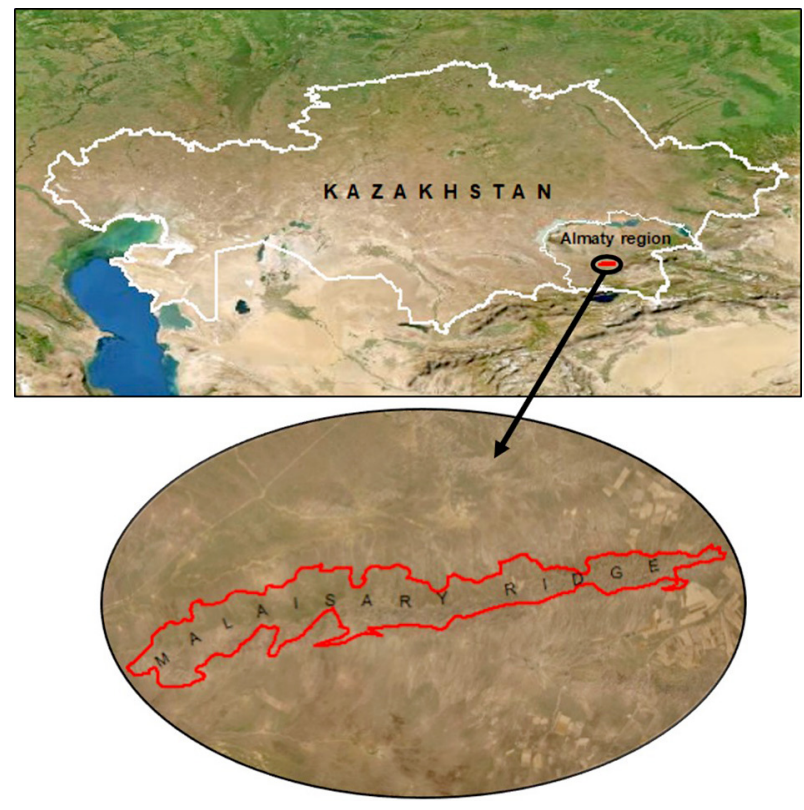

Figure 1. Malaisary ridge location
Due to favorable natural conditions, Malaisary ridge is the area of active development of farming economy (mainly pasturing). Apart from that, the numerous field roads are crossing the ridge. Increase of anthropogenic load and physical-geographical specific of Malaisary ridge are contribute to occurrence of relief forming processes in particular - gully erosion. For the rational use of foothills territories and preservation of ecological sustainability, the complex analysis and study of all factors of erosion potential of the ridge are required.

\section{Object of research}

In orographic relationship the described territory is covering western ridges of Zhetysu Alatau, stretching to Ile valley and representing a number of mountain ridges of almost latitudinal direction, divided by the intermontane valleys.

Malaisary ridge is stretched in latitudinal direction with the length up to $80 \mathrm{~km}$ and width of $8-10 \mathrm{~km}$ and in the west is covered by Ile valley alluvium. The altitude is $1100-1400 \mathrm{~min}$ the east and $700-850 \mathrm{~min}$ the west. Relative height is about $100-200 \mathrm{~m}$.

Climate of studied region is continental. Winter is relative soft and dry; spring is early, summer is long and hot. Average annual temperature is $+6.8^{\circ} \mathrm{C}$. Sum of average annual precipitation is $200-250 \mathrm{~mm}$. According to climate classification (Koeppen-Geiger) for the years 1986-2006 the studied region belongs to BSk type of climate (Kottek et al., 2006).

Malaisary ridge is young formation which is appeared in the results of new tectonic processes. It is represented by low mountains sculpture forms with intensive erosive dissection. The general morphological law of the ridge is slopes asymmetry: the southern one is more steep and high, the northern is more gently sloping and low. Morphology of the low mountains relief shows that the main morphogenesis factors are tectonic movements and erosion. Mountain massif of the ridge is relative low and as a result, the runoff from the highland of Zhetysu Alatau is practically absent here and local precipitation is too little. That is why the conditions for ground waters formation in this region are very unfavorable.

In geological structure are present the rocks of Neogene, Cretaceous, Triassic, Permian and Carboniferous periods. Neogene $\left(\mathrm{N}_{1}, \mathrm{~N}_{2}\right)$ horizon is mainly presented by red color clays, sandstones, gravelite, conglomerates, gravel-sand-pebble material. Upper Cretaceous deposits $\left(\mathrm{K}_{2}\right)$ are sandstones, gravekite, conglomerates, sands, clays with the layer thickness up to $85 \mathrm{~m}$. Section of Early (Triassian deposits $\left(\mathrm{T}_{1}-\right.$ malaisary suite) is represented bysandstones, tuff sandstones, tuffite, tuff, quartz porphyry, with the layer thickness between 200-210 m. Permian deposits $\left(\mathrm{P}_{1}, \mathrm{P}_{2}\right)$,are performed by sedimentary and volcanogenic formations (karashokinskaya, dosovskaya, krasnogorskaya and kyzylkainarskaya suites), with the layer thickness from 550 to $960 \mathrm{~m}$. Section of konurolenskaya suite $\left(\mathrm{C}_{3}-\mathrm{P}_{1} \mathrm{kn}\right)$ is presented by porphyry, tuff, ignimbrite, tuff sandstone, tuff gravelstone, with the layer 
thickness of 500-600 m. Upper Carboniferous deposits $\left(\mathrm{C}_{3} \mathrm{mt}_{2}\right.$ matai suite) are presented byandesite porphyry, tuff, tuff breccias, andesite-basalt, with the layer thickness of $150 \mathrm{~m}$. Early Permian and Upper Carboniferous intrusions are distributed relative rare and represented by syenite-diorite and diorite.

Deposits of Quaternary period in studied region take important place. They are represented by alluvial, eolian and dealluvial-proluvial origin types. Alluvial deposits of Early and Middle Quaternary period and of modern age composite above flood-plain terraces and valleys of rivers Bizhe, Shengeldy, Kerbulak, Sarybulak, Ile and represented by pebbles, gravel, sands, aleurite, clayed sand, loess loamandsilt with the layer thickness from 6 to $14 \mathrm{~m}$. Eolian accumulations of modern age with the layer thickness 6-10 mare presented by sand massifs of Moiynkum. Dealluvial-proluvialdeposits from Middle Quaternarytill Upper Quaternary-modern agecomposite slopes and foothills of the mountains, dissected by dryravines. They are represented by sand-pebble-detritusmaterial with the layer thickness from 1 to $20 \mathrm{~m}$ (Figure 2).

Soil cover of Malaisary ridge is characterized by slightly calcareous sierozem and mountain chestnut soil, which have good physical characteristics and they are the main objects of land use (Mairin et al., 1961).

Sierozem soils are developed on loess-likeloam of foothill plain. Humus horizon has light grey color, thickness of layer is $26-28 \mathrm{~cm}$, humus content in top layers of horizonis from 1.6 to $1.9 \%$. Top layer of humus horizon is slightly grass-covered and disintegrated for flaky-lamellar partings. In the depth from $52-60$ to $110-118 \mathrm{~cm}$ there is very compact illuvial carbonate horizon with the big number of beetles cells very dense consolidated by carbonate horizon.
Below the carbonate horizon is located loess-like loam. Carbonate content in the top layers makes $2-2.5 \%$ and they are referred to slightly calcareous sierozems. By specific origin characteristics A. N. Rozanov attributedthese soils to the subtype of northern or semirechenskiy sierozems. In the vegetation cover prevail Festúca valesiáca, Artemisia sublessitigiana with the certain amount of Vitex ágnus-cástus and Ceratocarpus, there are also ephemeras such as Poa bulbosa, Brómus, Cárex and Papáver (Lomonovich, 1963).

By geomorphological description the main part of the ridge Malaisary is attributed to the low mountains denudation coarse topography, except for elevated parts which are attributed to middle mountains erosion-denudation coarse topography (Figure 3).

Middle mountains erosion-denudation coarse topography is transition type of relief and characterized by more leveled forms in comparison to high mountain relief. The slopes of such relief type have gently sloping convexo-concave surface, watershed parts are considerably leveled, and northern slopes are gentler sloping than southern ones which have narrow gorges, pointed rocks and vertical terraces. Altitudes of middle mountains relief are in the limits of $800-1400 \mathrm{~m}$ and relative height is about $100-150 \mathrm{~m}$.

Relief of Malaisary ridge is gradually changes from middle mountains to low mountains, in some places transition is sharp and stepped. Surface of low mountains denudation slightly dissected relief is leveled, covered by the net of gullies and ravines. Such a type is more characteristic for the northern slopes of the ridge. Altitudes of low mountains relief are in the limits from 750 to $1000 \mathrm{~m}$, relative height is about 75-100 m (Mairin et al., 1961).

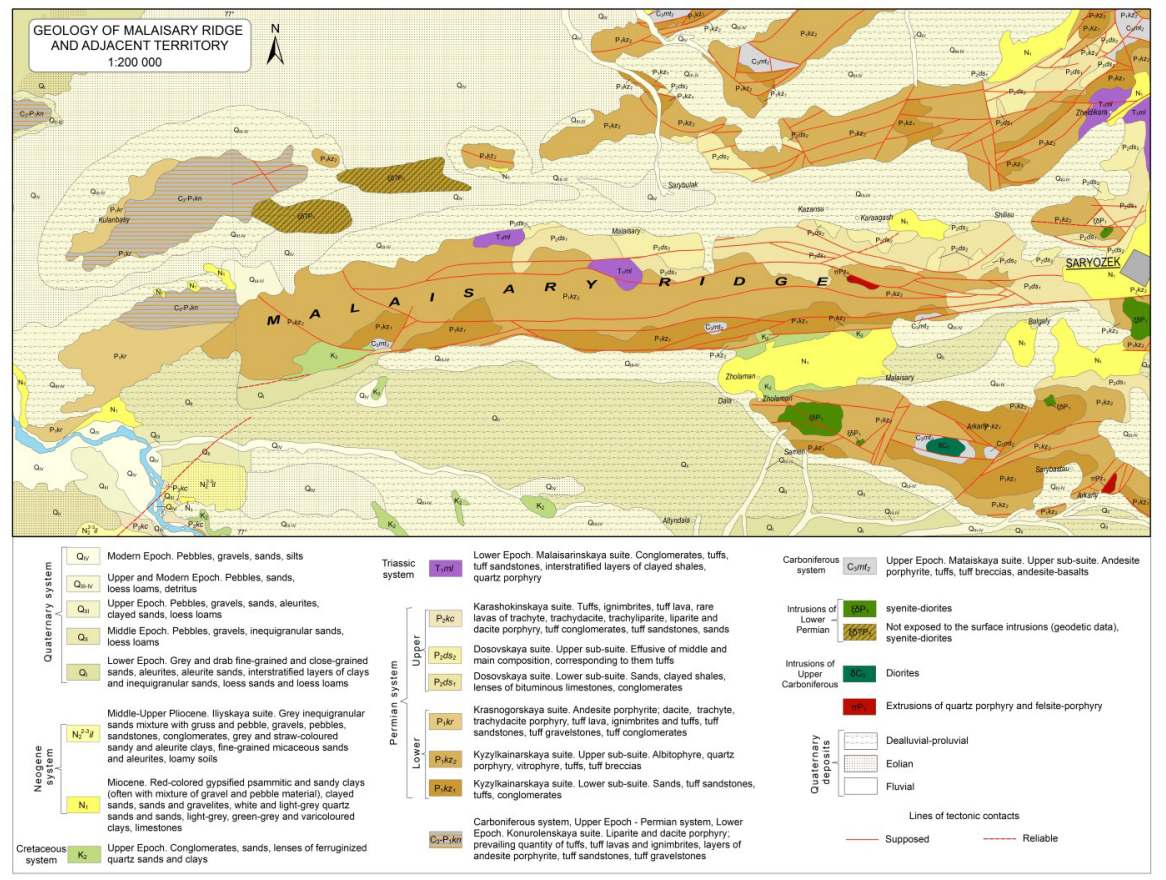

Figure 2. Geological structure of the ridge Malaisary and surrounding territory 


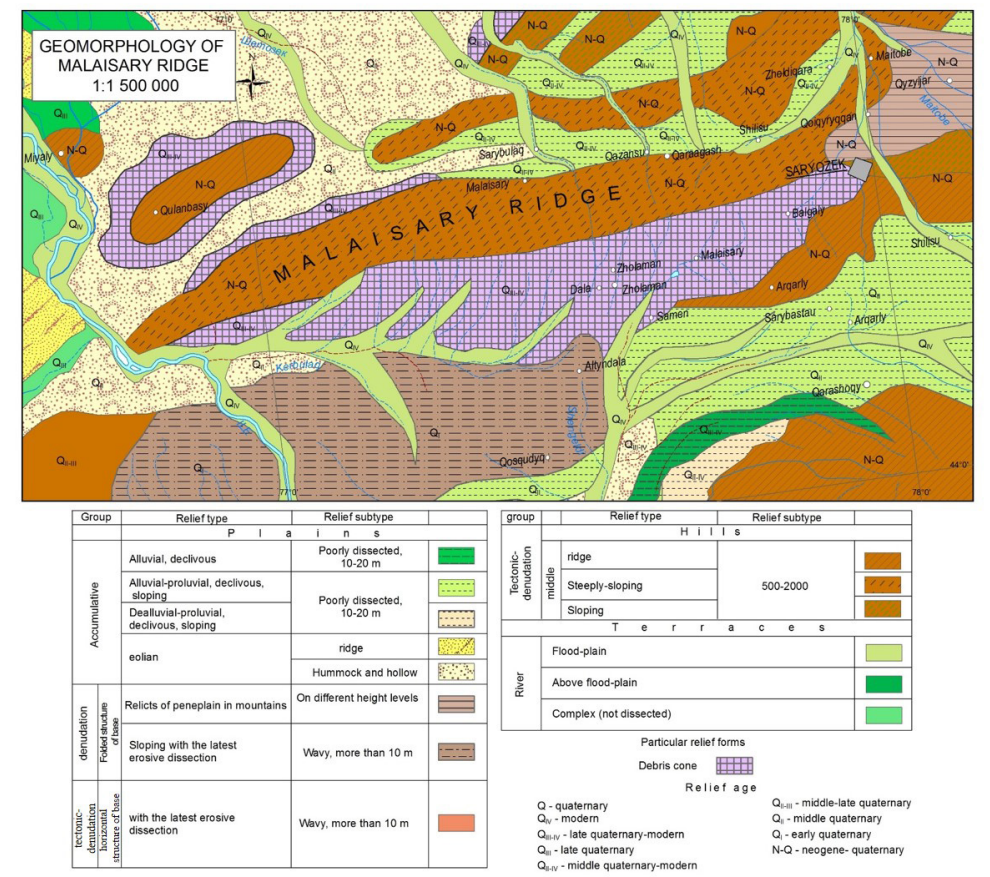

Figure 3. Geomorphological map of Malaisary ridge

\section{Research methods}

Nowadays, for the gullies study are applied different methods, but among them, very effective are methods with the use of GIS-technologies. They are: Determination and mapping of gullies using images from open sources such as Google Earth and ASTER GDEM; pixel analysis of images based on methods of remote sensing data; automatic mapping of gullies, objects-oriented methods; topographic method based on DEM for determination of gullies elements (Liu et al., 2018); use of terrestrial 3D laser scanner for the monitoring of erosion processes (Li et al., 2017; Gafurov et al., 2017; Goodwin et al., 2017).

Year by year, due to development of measuring devices and data of remote sensing, the study of gully erosion is becoming more qualitative and accessible. Qualitative information with the images of high resolution would allow identifying more exactly the borders of gullies, to classify and determine the exact sizes for the studying of intensity and later on for forecasting of development of gully erosion.

Field methods are based on definition of borders of gullies, morphometric and morphological parameters (length, depth, width and volume of gully), the final goal of which is determination of dynamic of gully erosion. For the field methods are used: plotting scales, flexible rulers, laser range finders, tachymeters, GPS and 3D terrestrial laser scanners (TLS). Field methods of gullies study are labour-intensive, time consuming and there are difficulties to use them for the big scale.

Peculiarity of the study is that for the first time in Kazakhstan the following different methods were used simultaneously to study gully erosion:

1) mapping, identification and monitoring of ravines using high-resolution satellite images using SAS. Planets of tware resources, ArcGIS and Google Earth Pro;

2) terrestrial laser scanning (TLS) for calculating washed-out soil and obtaining transverse and longitudinal profiles of ravines;

3) the classical method of benchmarks installing on the tops of ravines to obtain the growth dynamics.

In this article attention is also paid to the natural factors of gully formation, such as climate, geological and geomorphological structure of the area, soil cover, vegetation.

The studied gullies are located in western part of Malaisary ridge where from 2012 to 2018 was conducted stationary monitoring (yearly in October) and additional study of gully erosion. During the study there were used field instrumental methods (monitoring at the key sites), mapping, GIS, satellite images processing with the use of ArcGIS, use of 3D laser scanner RIEGL VZ-4000, comparative analysis and results description.

The use of the method of terrestrial laser scanning in the study of erosion processes allows us to quickly obtain three-dimensional data with high accuracy, showing changes in the landscape, characterizing the process of denudation and accumulation. The method of terrestrias laser scanning made it possible to determine the quantitative characteristics of the development of erosion processes, in particular, the volume of washed out soil, linear changes in the transverse and longitudinal profiles. The TLS method consists of 3 main stages: selection of monitoring sites and scanning points; laser scanning of selected areas using VZ-4000 3D scanner with the maximum coverage of the scanned object; processing of the received data using the RiSCAN PRO program. 
In the last time, taking into account the rapid development of GIS technology, the monitoring of gully erosion processes using satellite imagery materials has become more accessible and reliable. Each year, the resolution and quality of sattelite images are increasing, thereby giving more opportunities for researchers to solve the assigned tasks in their research. Using ultra-high resolution satellite images (1.65-0.4 meters) from open sources, researchers have the opportunity to map and monitor gully erosion in more detail.

Our base research method was the visual identification of linear erosion (ravines and water stream erosion) by visual analysis of the screen image of high-resolution satellite images with verification of the results in the field at selected key areas. Satellite images in digital form and for different time intervals allowed us to determine various indicators of gullies formation: the density of the ravine network $\left(\mathrm{km} / \mathrm{km}^{2}\right)$, the density of ravines (unit $/ \mathrm{km}^{2}$ ), areal and linear dynamics of the ravine network.

The most informative in the study of gully erosion are autumn and spring satellite images. The stages of development of ravine forms are well traced in summer photographs, but their disadvantages include the fact that under dense vegetation, it is difficult to determine the small ravines. The condition for improving the quality of the interpretation results is the presence of several images obtained in different seasons of the year. In the software resource SAS. Planet that we used, there were images of the required quality, they are provided by various resources, such as Google, Yandex, Bing, ESRI. Sattelite images were obtained from WorldView-2, WorldView-3 and GeoEye-1 satellites. To compare those satellite images, the software resource Google Earth Pro was used.

The software resource ArcGIS (ArcMap application, Spatial Analyst module) was used to obtain a digital elevation model. Later, the maps of horizontal and vertical dissection were obtained, which were very important for determining the degree of development of gully erosion.

\section{Results and discussion}

Gully erosion on the Malaisary ridge is mainly actively developing in the natural conditions on foothill plains (starting by the steepness of the slope from $0.5^{\circ}$ ), on the slopes of middle mountains and low mountains, in river valleys (along the benches of the river terraces), as well as in the results of economic activity in the pastures, field roads and ditches at the sides of the roads.

Formation and development of gully erosion depend on many natural and anthropogenic factors. Leading factors for the development of gully erosion are relief, erosional features of the rock, climatic conditions, hydrological conditions of runoff formation, erosion-preventive resistance of the soils, vegetation cover and economic activity of land use. Mentioned factors are standard factors for the development of majority of gullies without dependence from geographical zones, but in the mountain and foothill territories they influence more dynamically because of the complex morphometric relief characteristics. Gullies of Malaisary ridge are mainly developing in Quaternary sediments (dealluvial, dealluvial-proluvial).

Territory of Malaisary ridge is about $1350 \mathrm{~km}^{2}$ and stretches in latitudinal direction. The northern and southern slopes of the ridge show very clear difference and because of that the development of gully erosion on the different slopes occurs with different intensity. Studied region of Malaisary ridge is characterized by wide distribution of gullies, which are different by length, depth, width and level of erosive activity. The altitude of the territory is 500-1000 a.s.l., length of the slopes from 3000 till $10500 \mathrm{~m}$. The slopes shape changes from convex to concave. Elevation difference and steepness of the slopes form $0.5^{\circ}$ to $3.2^{\circ}$ creates favorable conditions for the formation of water streams exceeding acceptable washing out rates for soils and grounds. In the top part of the ridge, outcropping of the rocks in particular cases creates more complex net of development of erosive-accumulative processes in the limits of gully bed.

According to climatic characteristics the studied site is related to arid zone. Amount of precipitation in Malaisary ridge is insignificant and that is connected with location of the territory in central part of the continent and remoteness from the oceans. In the studied territory the average annual precipitation is varying in the limits of 200-250 $\mathrm{mm} /$ year, from them the precipitation of warm period of the year (April-October) is $100-150 \mathrm{~mm}$, snow melting occurs from the end of February till the middle of March (Institut Geografii, 2010). By the analysis of within-year distribution of precipitation we could see that maximum of precipitation, according to monitoring of located near meteorological station (Kapshagai) are in spring (April-May) and autumn (October-November). I these months the main stage of erosive activity of studied gullies is progressing. However in other months of the warm season the activity of gully erosion could increase due to rainfalls in the areas where intensity of precipitation is high. The active development of gully erosion is occurring during infrequent but heavy rainfall. During the rainfalls the gullies are growing in the top parts and in the depth and after that during the droughts there is a period of deceleration in growth. The main reason of such processes is global climate change. According to the data of journal "Geophysical Research" (USA), the half of annual amount of precipitation is reached in 12 days, and by the end of the century that period would be reduced till 11 days. To the annual amount of precipitation contribute disproportionately only a few days with heavy rainfall, but majority of days with small portions of rain contribute much less. Those data is based on the data of 185 meteorological stations for the years 1999-2014 and satellites data from "Tropical Rainfall Measuring Mission". The scientists concluded that such changes could bring to the big floods and other consequences in the future (Pendergrass \& Knutti, 2018).

It is reasonable to note that during "dry" months, from June till August, in morphogenesis and sediments 
formation participate eolian process, which is leading to gradation of gullies edges. Many scientists noted the main paradox of arid countries: rich diversity and visible freshness of the forms of modern landscape, created by erosion of temporal streams in the conditions of very dry climate with low precipitation (Lyubimov, 2002).

To obtain data on the current state of the ravines of the Malaisary ridge, the available sattelite images of 20132018 from the SAS. Planet software resource (sattelite images: Landsat 7.8 Sentinel 2, Yandex, Bing) were used and the Google Earth Pro software resource was used to compare those sattelite images. By determining ravine forms from satellite images, an important stage is the formation of a system of decryption signs. Deciphering features of ravines include a characteristic form with clear, geometrically well-defined boundaries; the presence of a clear edge and a clear thalweg line; contrasting tones and colors on different sides of the ravine, which testify to the V-shaped profile of the ravine, and the more contrasting they are in the picture, the greater the depth of the ravine; the presence of individual lighter areas on the slopes of the ravine is corresponding to the exposed (free from vegetation) areas. At the same time, it is very important to distinguish them from other linear forms of water erosion. So, a gully differs from a ravine in an insignificant depth, which does not exceed $1.5 \mathrm{~m}$, and a width of less than $3 \mathrm{~m}$.

In Malaisary ridge area, using satellite images, were determined and counted 58 gully-ravine nets, from them 39 on the northern slope and 19 on the southern one. On the northern slope the length of gully-ravine net is varying from $88 \mathrm{~m}$ to $21700 \mathrm{~m}$ and has the following morphometric characteristics: in the top part the depth is from $1.5 \mathrm{~m}$ to $10.8 \mathrm{~m}$, width is from $3.2 \mathrm{~m}$ to $37.4 \mathrm{~m}$; in the middle part the depth is from $1.3 \mathrm{~m}$ to $16.4 \mathrm{~m}$, width is from $2.7 \mathrm{~m}$ to $58.7 \mathrm{~m}$; in the lowest part the depth is from $0.9 \mathrm{~m}$ to $21.5 \mathrm{~m}$, width is from $4 \mathrm{~m}$ to $97.3 \mathrm{~m}$. On the southern slope the length of gully-ravine net is varying from $63 \mathrm{~m}$ to $1859 \mathrm{~m}$ and has the following morphometric characteristics: in the top part the depth is from $1.5 \mathrm{~m}$ to $4.3 \mathrm{~m}$, width is from $3.8 \mathrm{~m}$ to $14.5 \mathrm{~m}$; in the middle part the depth is from $1.7 \mathrm{~m}$ to $6.7 \mathrm{~m}$, width is from $3.7 \mathrm{~m}$ to $23.4 \mathrm{~m}$; in the lowest part the depth is from $1.4 \mathrm{~m}$ to $6.9 \mathrm{~m}$, width is from $4.3 \mathrm{~m}$ to $38.5 \mathrm{~m}$. In the Table 1 are provided morphometric characteristics of studied gully-ravine net of Malaisary ridge.

To obtain a more detailed digital model of the ravine relief, a high-precision 3D laser scanner RIEGL VZ-4000 was used. The data obtained after laser scanning of ravines in the form of clouds points were processed in the RiSCAN PRO program version 2.8.2. The result of the scan was quantitative data on the internal volume of the ravine located on the Malaisary ridge for 2017 and 2018 observation years. As a result of processing field data for the periods 2017-2018 using the TLS method, the following values were obtained:

1) the internal volume of the ravine for 2017 (as of November 5) is $5088.7980 \mathrm{~m}^{3}$;
Table 1. Morphometric characteristics of gully-ravine net of Malaisary ridge

\begin{tabular}{|c|c|c|c|c|c|c|c|}
\hline \multicolumn{8}{|c|}{$\begin{array}{l}\text { Number and morphometric characteristics of gullies on the } \\
\text { northern slope of Malaisary ridge }\end{array}$} \\
\hline \multirow{2}{*}{ No. } & \multirow{2}{*}{$\begin{array}{l}\text { Length, } \\
\text { m }\end{array}$} & \multicolumn{2}{|c|}{$\begin{array}{l}\text { Top part of } \\
\text { gully }\end{array}$} & \multicolumn{2}{|c|}{$\begin{array}{l}\text { Middle part of } \\
\text { gully }\end{array}$} & \multicolumn{2}{|c|}{$\begin{array}{l}\text { Lowest part of } \\
\text { gully }\end{array}$} \\
\hline & & $\begin{array}{c}\text { debth, } \\
\mathrm{m}\end{array}$ & $\begin{array}{l}\text { width, } \\
\mathrm{m}\end{array}$ & $\begin{array}{c}\text { debth, } \\
\mathrm{m}\end{array}$ & $\begin{array}{c}\text { width, } \\
\mathrm{m}\end{array}$ & $\begin{array}{c}\text { debth, } \\
\mathrm{m}\end{array}$ & $\begin{array}{l}\text { width, } \\
\mathrm{m}\end{array}$ \\
\hline 1 & 321 & 9.7 & 18.8 & 5.7 & 16.9 & 4.2 & 12.2 \\
\hline 2 & 615 & 4.2 & 10.8 & 4.4 & 13.55 & 3.9 & 9.2 \\
\hline 3 & 339 & 2.4 & 4.5 & 2.9 & 6.1 & 2.2 & 5.5 \\
\hline 4 & 365 & 3.1 & 8.6 & 2.6 & 7.9 & 2.2 & 5.2 \\
\hline 5 & 478 & 4.3 & 17.4 & 2.9 & 9.9 & 2.95 & 8.1 \\
\hline 6 & 346 & 3.5 & 9.2 & 3.1 & 8.4 & 6.1 & 19.5 \\
\hline 7 & 897 & 2.5 & 10.4 & 5.3 & 14.7 & 4.7 & 16.3 \\
\hline 8 & 310 & 3.6 & 8.4 & 3.8 & 12.3 & 2.8 & 8 \\
\hline 9 & 5925 & 9.6 & 23 & 6.3 & 16.2 & 5.3 & 11.6 \\
\hline 10 & 282 & 5.6 & 14.7 & 6.9 & 21.8 & 4.4 & 11.6 \\
\hline 11 & 641 & 2.3 & 5.8 & 3.1 & 6.3 & 2.7 & 7.8 \\
\hline 12 & 221 & 2.4 & 6.2 & 2.6 & 10.6 & 2.8 & 7 \\
\hline 13 & 301 & 2 & 9.5 & 3 & 11.9 & 2.8 & 6.6 \\
\hline 14 & 351 & 1.8 & 4 & 2.1 & 4.2 & 1.2 & 4.5 \\
\hline 15 & 125 & 2.34 & 5.5 & 4.2 & 14.3 & 3.9 & 12.8 \\
\hline 16 & 15300 & 7.1 & 37.4 & 8.4 & 23.9 & 10.5 & 41.5 \\
\hline 17 & 254 & 2.2 & 4.8 & 1.3 & 2.7 & 2.5 & 5.1 \\
\hline 18 & 548 & 4.4 & 11.7 & 3 & 7.2 & 2 & 8.8 \\
\hline 19 & 21700 & 11.9 & 26.9 & 12.9 & 47.4 & 21.5 & 97.3 \\
\hline 20 & 501 & 12.1 & 24 & 16.4 & 35.4 & 15.2 & 38.7 \\
\hline 21 & 1291 & 6.3 & 12.8 & 10.2 & 25.4 & 6.9 & 19.7 \\
\hline 22 & 83 & 3.3 & 5.8 & 3.9 & 6.7 & 2.1 & 4 \\
\hline 23 & 124 & 2.1 & 3.9 & 3.1 & 5.6 & 3.5 & 6.4 \\
\hline 24 & 176 & 2.4 & 5.2 & 2.2 & 6.8 & 3.9 & 10.5 \\
\hline 25 & 1701 & 2.6 & 9 & 4.7 & 21.8 & 6.8 & 18.4 \\
\hline 26 & 269 & 4.05 & 11.4 & 6.1 & 24.8 & 7.8 & 30.9 \\
\hline 27 & 180 & 1.9 & 4.1 & 5.5 & 11.5 & 3.4 & 7.5 \\
\hline 28 & 954 & 4.7 & 10.5 & 11 & 25.6 & 10.2 & 36.3 \\
\hline 29 & 908 & 2.8 & 11.1 & 7.2 & 16.7 & 1.9 & 14.8 \\
\hline 30 & 263 & 3.5 & 9.3 & 5.6 & 16.3 & 5.9 & 21.6 \\
\hline 31 & 2757 & 10.8 & 29.5 & 14.6 & 58.7 & 8.1 & 24.9 \\
\hline 32 & 180.1 & 2.8 & 7.4 & 4.6 & 12.4 & 2.5 & 6.1 \\
\hline 33 & 203 & 1.5 & 3.2 & 1.4 & 3.5 & 0.9 & 2.25 \\
\hline 34 & 88 & 3.4 & 6.1 & 2.9 & 7.1 & 1.6 & 4.2 \\
\hline 35 & 486 & 3.8 & 11.2 & 5.3 & 14 & 3 & 9.6 \\
\hline 36 & 355 & 3.9 & 9.5 & 4 & 6.9 & 2.4 & 4.9 \\
\hline 37 & 255 & 3.1 & 8.8 & 2.6 & 5.3 & 1.9 & 5.8 \\
\hline 38 & 671 & 3.8 & 9.6 & 4.7 & 9.1 & 3.2 & 16.4 \\
\hline 39 & 779 & 4.2 & 11.1 & 4.7 & 13 & 2.2 & 5.8 \\
\hline
\end{tabular}


End of Table 1

\begin{tabular}{|c|c|c|c|c|c|c|c|}
\hline \multicolumn{5}{|c|}{ Number and morphometric characteristics of gullies on the } \\
southern slope of Malaisary ridge
\end{tabular}

2) the internal volume of the ravine for 2018 (as of October 8) is $5220.817696 \mathrm{~m}^{3}$;

3) the washed-out volume of soil during the observation period is $132.019696 \mathrm{~m}^{3}$.

Results from the use of laser scanning systems show that fast growing ravines can be identified and quantified

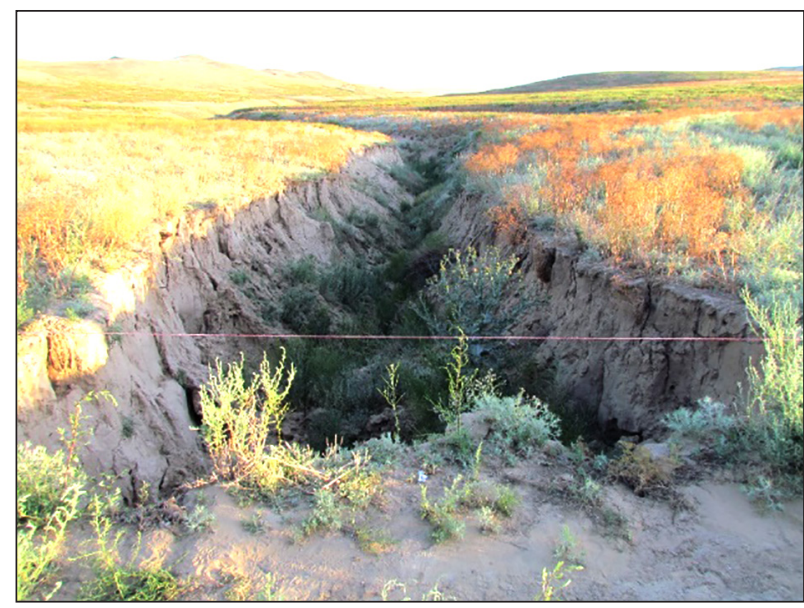

Top part of gully (2013) using this convenient method. Based on the analysis of digital elevation models of different years, obtained by the TLS method, it is possible to estimate the rate of soil washout and the increase in the tops of ravines. In the ravine of the Malaiysary ridge, under the influence of water erosion, the washed-out volume of soil for 1 year of observation (2017-2018) made $130.02 \mathrm{~m}^{3}$ (for $122 \mathrm{~m}$ of the length of the ravine). Important quantitative data about the amount of washed out soil are the consequences of erosion processes on the Malaisary ridge. During erosion processes, the energy of water during heavy rains washes away and weakens the tops, edges, slopes and bases of ravines, which leads to a change in their morphology and morphometry, which further leads to an increase in the dynamics of changes and development of the ravine system.

During the field works once a year the was done following: determination of linear and areal growth of gullies in western part of the ridge Malaisary as well as determination of deepening and change of accompanying processes occurring on the slopes. Linear growth of gullies was determined by the means of benchmark installation. In the top of gully were installed stationary benchmarks with the help of which later on there were measured distances from the benchmarks till the top of gullies. Rate of linear gullies growthis one of the indicators of landscape change, morphogenesis and interconnection with the climate change. In 2003 the field works showed that the top part of the gully-ravine net started developing in western and eastern directions and as a result formed different tops. Beginning of branching of the top part of gully is shown in the Figure 4 . Those tops were conditionally named top A and top B. Later on for the monitoring of dynamic we installed different benchmarks on the top A and top B. In the Figure 5 we can see approximately the same dynamic of linear growth in different tops of the gully and that is reasonable because they have the same factors of gully development. Linear growth of the top of studied gully made from 0.1 to $0.83 \mathrm{~m} /$ year (Table 2), by the average annual growth was $0.41 \mathrm{~m} /$ year (for the period 2012-2018).

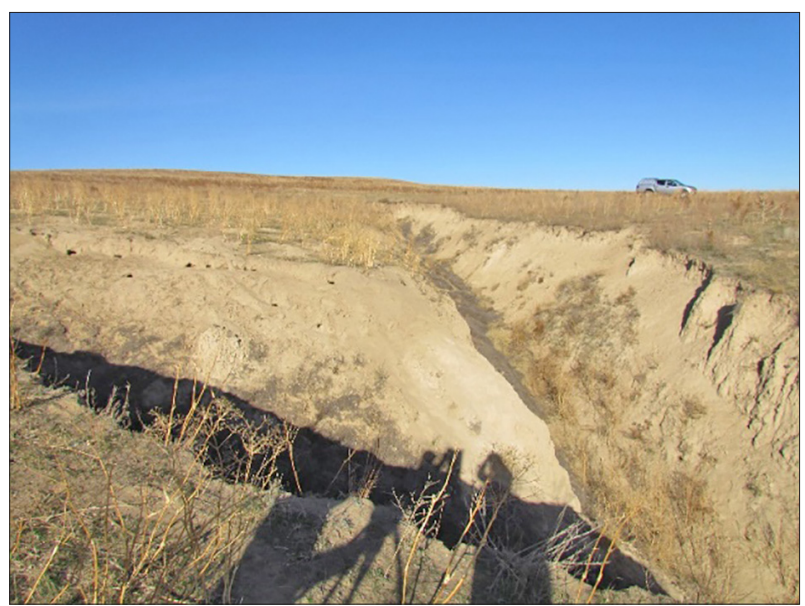

Top part of gully (2017)

Figure 4. Beginning of branching of the top part of studied gully 


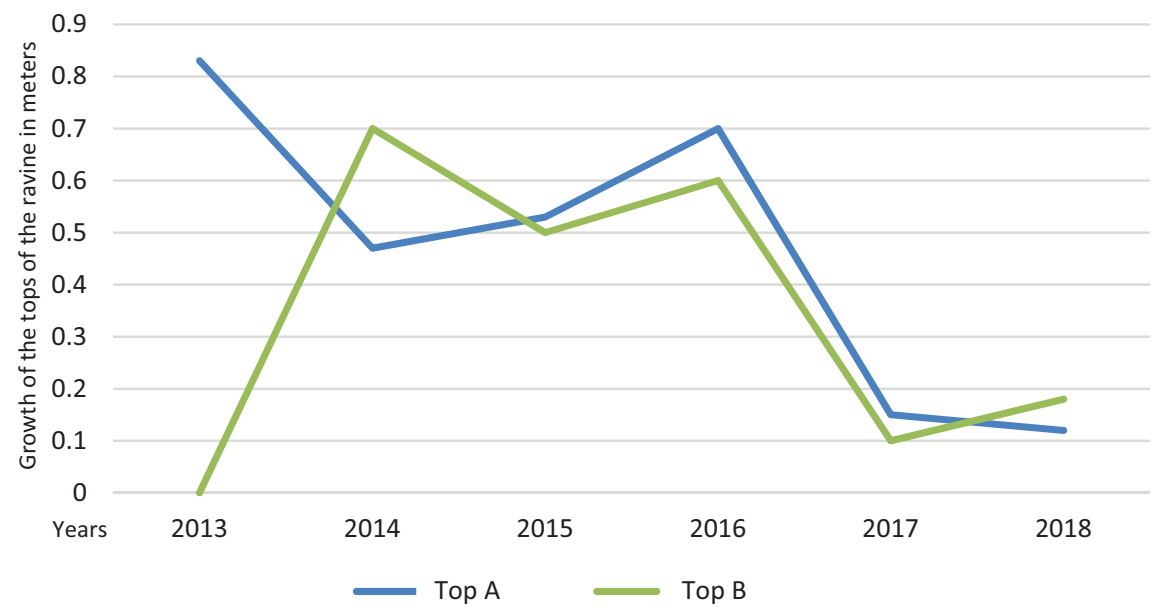

Figure 5. Diagram of growth of top part of gully in the western part of Malaisary ridge

Table 2. Growth of the top part of gullies (m)

\begin{tabular}{|c|c|c|c|c|c|c|c|}
\hline Name of the key site & Top & 2013 & 2014 & 2015 & 2016 & 2017 & 2018 \\
\hline \multirow{2}{*}{$\begin{array}{l}\text { Malaisary ridge, } 51.7 \mathrm{~km} \text { to the north from Kapshagai } \\
\text { town (Balksh region), No. by GPS: 440-442 }\end{array}$} & $\mathrm{A}$ & 0.83 & 0.47 & 0.53 & 0.7 & 0.15 & 0.12 \\
\cline { 2 - 9 } & B & 0 & 0.7 & 0.5 & 0.6 & 0.1 & 0.18 \\
\hline
\end{tabular}

Averaged linear growth of the top part in other regions of the Earth makes $0.89 \mathrm{~m} /$ year, but the values of fluctuation are very high - from 0.01 to $135.2 \mathrm{~m} /$ year (Vanmaercke et al., 2016). Average annual growth of studied gully 2 times less than averaged value for the Earth and that is explained by location of gully in the arid zone. Taking into account that in the period from 2013 to 2018 occurred climatic changes connected with global warming of climate (increase of temperature in winter months), we could assume that the mentioned factor had an impact on general decrease of the rates of gully growth. For the further study of the rates of gully grows the analysis of hydrometeorological parameters and conditions of land use in the catchment area of gully is required.
Studied gully has steep symmetric slopes (up to $70^{\circ}$ ), width in the top part is from $5.3 \mathrm{~m}$ to $181.5 \mathrm{~min}$ the widest part, depth in the tor part is $1.9 \mathrm{~m}$, in the middle -10.4 mand in the lowest part $-14.2 \mathrm{~m}$. Total length by thalweg is $4042 \mathrm{~m}$. Fall: minimal is $0.6^{\circ}$; maximalis $6.7^{\circ}$; average is $0.3^{\circ}-2.6^{\circ}$. Catchment area makes $2.36 \mathrm{~km}^{2}$. Basis of gullyravine net of the ridge is often leveled sides of foothill plains, dry river-beds and thalwegs.

Cross-sections have mainly V-shapes, but could have also canyon-shapes and box-shapes with straight and steep slopes. Cross-section of gullies could change from $\mathrm{V}$-shape in the top part to U-shape in the lowest part (Figure 6). Longitudinal sideview is stepped, steep, bowshaped,and has quite steep thalweg. View of gully net in

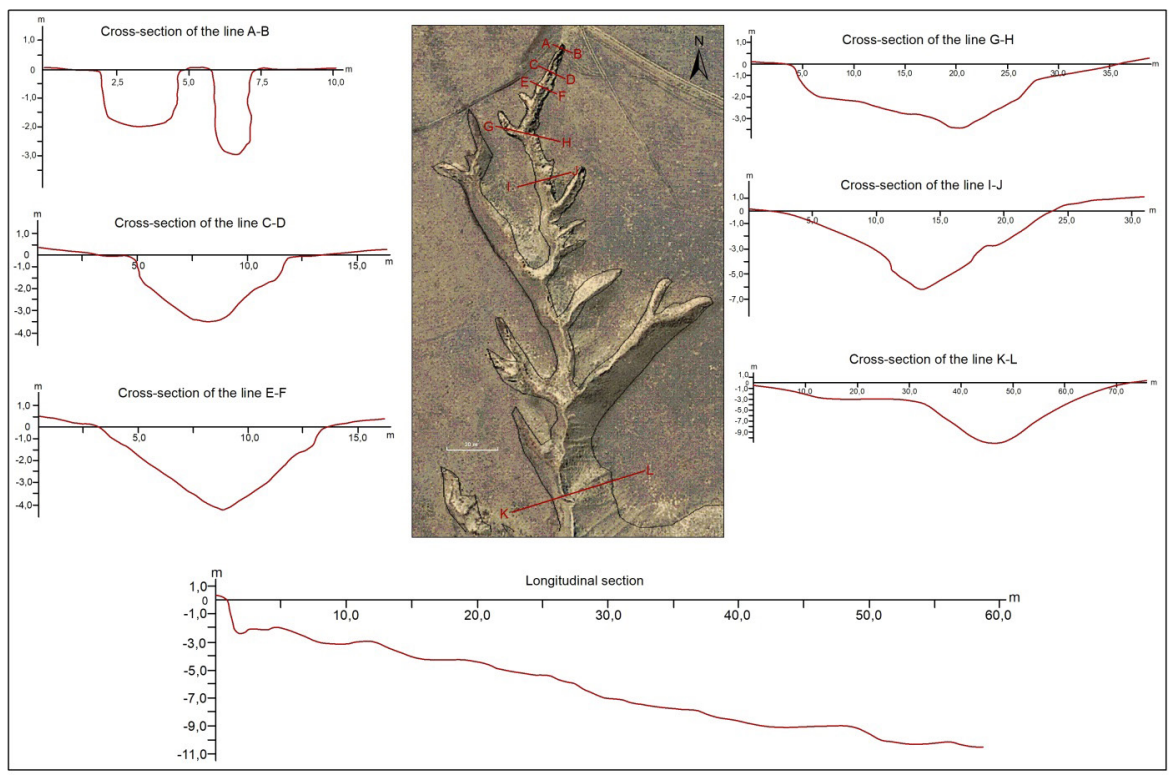

Figure 6. Cross-section and longitudinal section of gully 


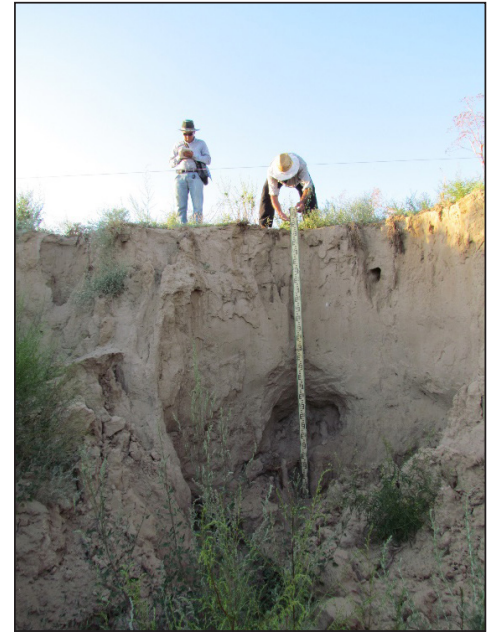

year 2013

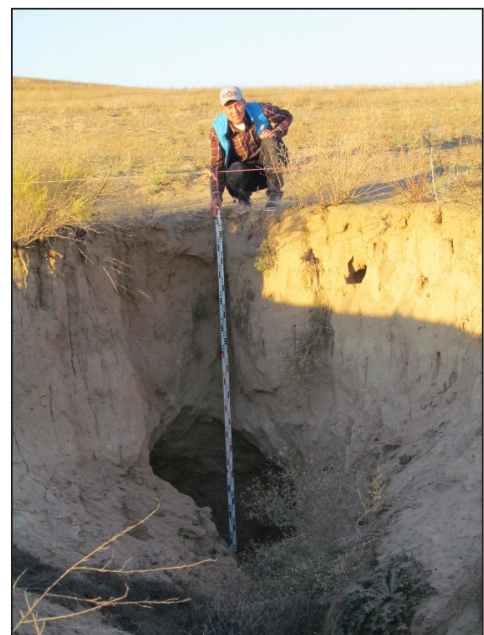

year 2018

Figure 7. Suffosion cavities in the top part of gully

the plan is tree-like and comb-shaped. Steepness of the slopes is varying from $1^{\circ}$ to $10^{\circ}$, but very rare could be found the steep slopes up to $30^{\circ}$. In the top parts of gully there are suffusion cavities (Figure 7).

By the gully erosion study, the modern GIS-technologies (satellite images of high resolution; 3D terrestrial laser scanning) allow to get morphometric characteristics of landscape environment, observe dynamic of change in time, providing objective and complex assessment. Process of satellite images processing includes following: choice of images, connection (transformation), development of principles decoding and digitization of landscape object (vectorization); development of the digital map structure; design of cartographic materials. By the definition and mapping of gully-ravine systems the following indicators were used: edges of the slopes, thalweg of gullies, color of slopes and bottom (Kyalykov, 2018).

Gully-ravine net of the ridge has a tree-like type (Figure 8). In the western part of the ridge the gullies and ravines are poor developed and in the top parts they are narrow and mostly have branchy shape.

One of the most intensive types of water erosion in agricultural lands is gully erosion. Maps of gully-ravine net are important precondition for the studying of gully erosion and land degradation. For the assessment of gully erosion of Malaisary ridge there was developed the map of gully-ravine net on the western slopes (Figure 8). On the map we can see considerable rate of gully erosion in the western part of the ridge, but such a situation we can meet quite often in the whole Malaisary ridge. The results of mapping could be used for the management of agricultural lands and for the preservation of the soils fertility.

For the gully erosion study and more detailed landscape characteristics the maps with morphometric characteristics are required. As the next step, using GIS development of DEM with horizontal resolution of $30 \mathrm{~m}$ we received maps of horizontal and vertical relief dissection. Methodic of mapping included estimation of landscape morphometric data by the means of Digital elevation model (STRM $30 \mathrm{~m}$ Digital Elevation). Indicators

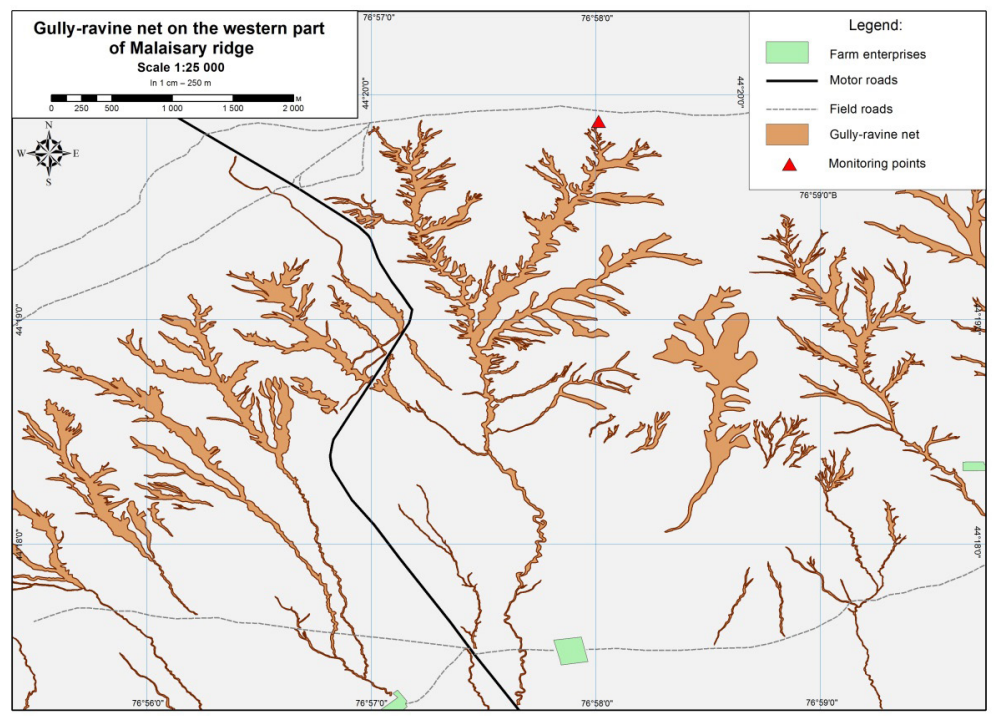

Figure 8. Gully-ravine net in the western part of Malaisary ridge 
of horizontal and vertical relief dissection along with the other parameters such as hypsometry, exposure, length of the slopes of erosive forms are determining the main natural processes of erosion development.

Erosion processes of Malaisary ridge are visually reflected on the map of horizontal dissection (Figure 9). That map allows also determining the quantitative characteristics of morphometric landscape parameters, defining its potential possibilities for the development of relief forming processes.

Density of erosion net is distributed by the studied region unevenly - from 0 to $4 \mathrm{~km}^{2}$. The values of horizontal dissection are increasing on the slopes of Malaisary ridge and decreasing on the low sites between riges. Analysis of the map or the ridge horizontal dissection allowed determining 4 categories of the sites, subjected to the gully erosion: weak erosion (density of horizontal dissection is less than $1 \mathrm{~km} / \mathrm{km}^{2}$ ); moderate erosion (density of horizontal dissection is $1-2 \mathrm{~km} / \mathrm{km}^{2}$ ); considerable erosion density of horizontal dissection is $2-3 \mathrm{~km} / \mathrm{km}^{2}$ ); Very intensive erosion (density of horizontal dissection is $3-4 \mathrm{~km} / \mathrm{km}^{2}$.

One of the most important morphometric characteristic of relief is vertical dissection. Values of vertical dissection show intensity of erosive processes of the territory.

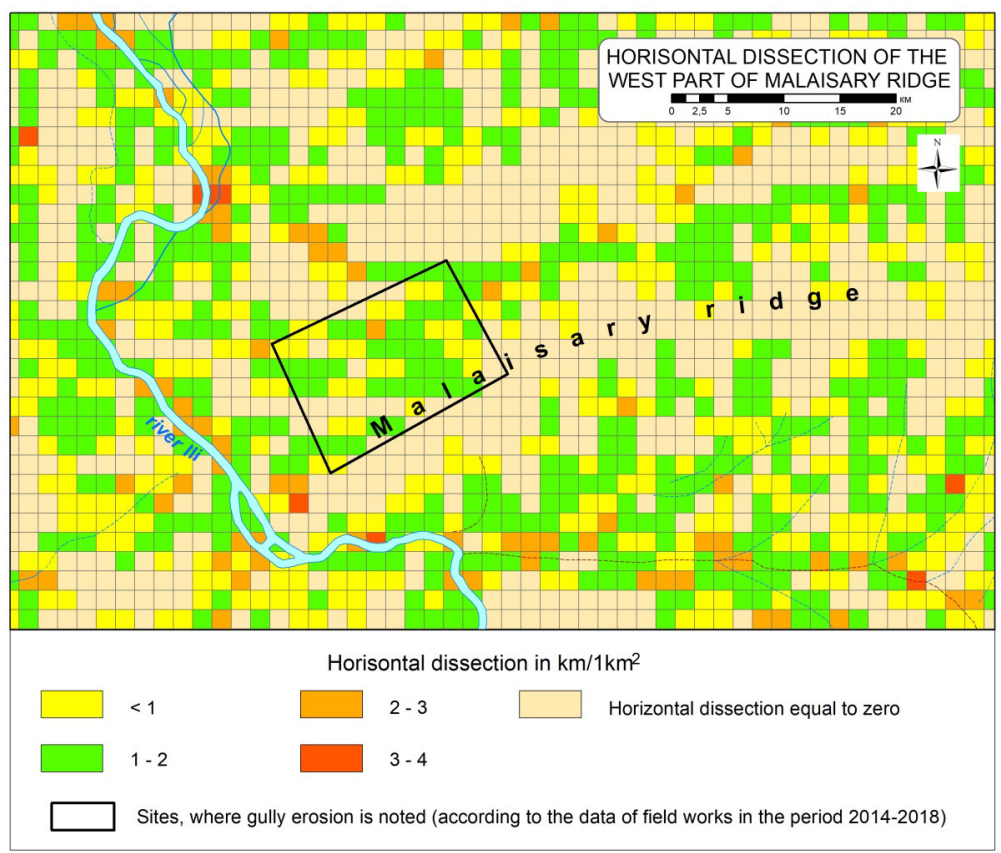

Figure 9. Horisontal dissection in the west part of Malaisary ridge

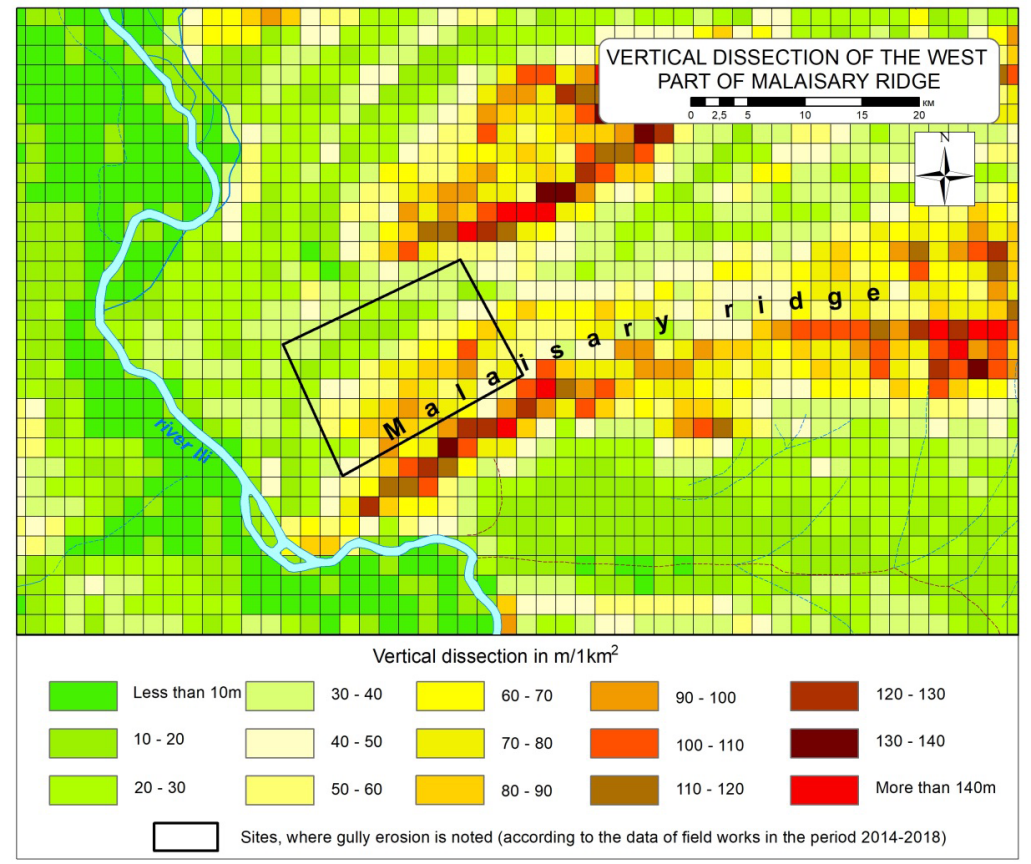

Figure 10. Vertical dissection of the western part of Malaisary ridge 
Activity of endogenous processes is closely connected with vertical relief dissection and results its values. Vertical relief dissection is determined by differences of surfaces attitudes between tops and bottoms.

Depth of relief dissection is varying in the limits of $10-140 \mathrm{~m} / \mathrm{km}^{2}$ (Figure 10). Big values of vertical dissection are belong to the slopes of peaks and slopes of foothills of the ridge where the erosive relief forms are mostly distributed. The biggest part of the ridge and adjacent territories are occupied by the sites with weak and moderate dissection (10-40 and 40-60 $\left.\mathrm{m} / \mathrm{km}^{2}\right)$.Sites with value of dissection $10-40 \mathrm{~m} / \mathrm{km}^{2}$ are distributed everywhere in depressions between the slopes. In the sites of considerable and intensive dissection $\left(60-80\right.$ and $\left.80-100 \mathrm{~m} / \mathrm{km}^{2}\right)$ the erosive processes occur in the highest degree. Apart from that in the form of separate spots on the top part of the ridge are presented the small sites with the very intensive dissection (110-140 $\mathrm{m} / \mathrm{km}^{2}$ and higher).

Maps of morphometric characteristics provide opportunity to assess development and distribution of erosive processes in the mountains and foothills of Zhetysu Alatau for the rational nature management in the conditions of intensive development of agricultural lands. Using the data of morphometric maps it is also possible to create the map of ratio of the areas occupied by the gullies and to create the "factor map" of gullies development (Veretennikova et al., 1998).

\section{Conclusions}

Monitoring of gully erosion on the ridge Malaisary shows that in the natural conditions erosive resistance of mountain regions is extremely insignificant, but by influence of anthropogenic factors it could be worsen.

Development of gully erosion of the mountain regions depends from the complex of natural and anthropogenic factors. To the unfavourable factors contributing to gully formation belong smorphometric relief characteristics, heavy shower type of precipitations in the warm season, spring snow melting, mechanical composition of loamy soils, small-scale absorbing capacity of the natural vegetation, pasturing and unorganized field roads.

Relief of the ridge with the complex morphometric characteristics is one of the leading factors of erosion. For the gully development the big influence make steepness, length and shape of the slopes. For mountain regions of the south-east Kazakhstan it was determined that by increase of the length and steepness of the slopes, the length, width and depth of erosive linear forms are also increasing. Apart from that, to the development of erosion considerable influence make exposure of the slopes. The received data confirm that the slopes of southern exposure more dissected by gullies and ravines than the northern once.

Catchment area of negative relief forms plays also important role, because in the low parts are developing gullies and ravines. By increase of catchment area the rates and sizes of gullies are also increasing. By catchment areas smaller than one hectar, the gullies are rather rare detected.
Erosion-preventive stability of sedimentary rocks in the mountain regions directly influence development of gully erosion. In the areas of development of loesses and loess-like loams which have weak erosion-preventive stability, the gully formation is developed very strong. But in the some areas of loess-like loams distribution the relief is not strong dissected by gullies and ravines and that is connected with climatic factors of the region.

Along with the natural factors, the anthropogenic factors could play important role in dynamic of gully erosion. Anthropogenic factor of gully development on Malaisary ridge are disturbance of natural vegetation cover as a result of pasturing and numerous unorganized field roads.

On the Malaisary region there are good developed farm enterprises which are mostly involved in pasturing. According to satellite images analysis there are 127 sites on the ridge, where exist farm enterprisesor sites which were used earlier as places for the cattle wintering and summering. There is approximately the same number of farm enterprises at the both slopes: in the southern slope they are 66 and in the northern slope they are 61. Active pasturing is increasing impact to the soil cover and lead to the erosion. Intensive pasturing also increases the quantitative proportions of the species composition of flora, transfer of alluvium by the wind and water and increases apparent density. In the future the mentioned disturbance could increase due to latest changes of global climate. Modern economy load to the mountain territories nowadays is higher in comparison to earlier periods due to the population growth and increasing demand of food.

High- and ultra-high-resolution sattelite images of the Earth make it possible to reliably identify gully erosional forms, including establishing their morphological and morphometric features on the slopes of mountains, plains and river basins. Approaches for geoinformation mapping of these ravine forms, as well as their dynamics using high-resolution satellite images, have been developed for the territory of the Malaisary ridge in key areas. The number of ravines was determined and the verification of decryption signs was carried out in the field conditions.

Using the obtained TLS data, we created the DEM of ravines for the selected monitoring sites. The results show that, with the suitable parameters, this method can quickly identify the most dynamically growing ravines and obtain the quantitative data of the washed-out soil volumes. Based on the analysis of the DEM as for 2017-2018, observations of the ravine of the Malaisary ridge, obtained using the TLS method, the washed-out volume of soil under the influence of water erosion was calculated for 1 year of observation (2017-2018), which is $130.02 \mathrm{~m}^{3}$ (for $122 \mathrm{~m}$ of the length of the ravine).

The systematic and long-term use of satellite imagery data and TLS method in the study of gully processes in mountainous areas makes it possible to control the danger of erosion processes, improve the subsequent characterization of the activity and morphometry of mountainous and lowland areas. The research methods used in the article make it possible to use it not only in relation to ravines, 
but also to other types of water erosion, for the better understanding of the phenomena associated with various processes of relief formation, such as landslides, rockfalls, avalanches, etc.

The received results allow concluding that gully erosion is the most considerable factor of transformation of the ridge relief. At present time the studied gullies of Malaisary ridge are active and have considerable erosive potential, they are practically not controlled by local authorities and could have a negative influence to the farming. Intensive gully erosion increases ecological tension of natural-anthropogenic environment in the region. Enlargement of the gully nets, their active developments are worsening quality of agricultural lands and could have a negative influence to the road and residential area infrastructure. In the last time the gully erosion control is not organized in spite of understanding that ecological and economic consequences of such a negative process could be considerable not only for the territory of Malaisary ridge but also for the all mountain and foothill territories of south-east Kazakhstan with its productive agricultural territories.

The results of the researches are useful for the planning and conducting of infrastructural works, for the management of agriculture, preservation of the soils and vegetation cover, ecological planning. In the mountain territories of south-east Kazakhstan the arrangements for the land protection in dependence from distribution and potential danger of gully erosion are required.

\section{Acknowledgements}

The research is done under the support of the project "Geographical bases of guaranteeing of safety of nature use of mountain and plain territories of Kazakhstan, project No. 0112PK00625".

\section{References}

Castillo, C., \& Gómez, J. A. (2016). A century of gully erosion research: Urgency, complexity and study approaches. EarthScience Reviews, 160, 300-319. https://doi.org/10.1016/j.earscirev.2016.07.009

Gafurov, A. M., Vedeneyeva, Ye. A., Yermolayev, O. P., \& Usmanov, B. M. (2017). Use of method of terrestrial laser scanning for the assessment of intensity of the modern exogenous processes. In Treshnikovskiye chteniya Materials of VII AllRussian Scientific-Practical Conference (pp. 14-17). Ulyanovsk (in Russian).

Goodwin, N. R., Armston, J. D., Muir, J., \& Stiller, I. (2017). Monitoring gully change: A comparison of airborne and terrestrial laser scanning using a case study from Aratula, Queensland. Geomorphology, 282, 195-208.

https://doi.org/10.1016/j.geomorph.2017.01.001

Institut Geografii. (2010). The national atlas of the Republic of Kazakhstan. A. R. Medeu (Ed.). Institute of Geography, Almaty. https://www.worldcat.org/title/national-atlas-of-therepublic-of-kazakhstan/oclc/767527874

Kosov, B. F., Zorina, E. F., Lyubimov, B. P., Morjakova, L. A., Nikol'skaja, I. I., \& Prohorova, S. D. (1989). Gully erosion. (R. S. Chalov, Ed.). Moscow State University Publishing House (in Russian). https://pb1lib.org/book/3049569/ a9e625? id $=3049569$ \&secret $=$ a9e625

Kottek, M., Grieser, J., Beck, Ch., Rudolf, B., \& Rubel, F. (2006). World Map of the Köppen-Geiger climate classification updated. Meteorologische Zeitschrift, 15(3), 259-263. https://doi.org/10.1127/0941-2948/2006/0130

Kyalykov, Ye. Ye. (2018). Implementation of methodic of terrestrial laser scanning and GIS by the study of gully erosion (Kazakhstan). Journal: Vestnik of Moscow University. Series 5. Geography, 5, 36-43 (in Russian).

Li, Z., Zhang, Y., Zhu, Q., Yang, S., Li, H., \& Ma, H. (2017). A gully erosion assessment model for the Chinese Loess Plateau based on changes in gully length and area. Catena, 148, 195-203. https://doi.org/10.1016/j.catena.2016.04.018

Liu, K., Ding, H., Tang, G., Song, Ch., Liu, Y., Jiang, L., Zhao, B., Gao, Y., \& Ma, R. (2018). Large-scale mapping of gully-affected areas: An approach integrating Google Earth images and terrain skeleton information. Geomorphology, 314, 13-26. https://doi.org/10.1016/j.geomorph.2018.04.011

Lomonovich, M. I. (Ed.). (1963). Ilijskaja dolina, ee prirodnye resursy [Ile valley, its natural resources]. Izd-vo AN Kazahskoj SSR (in Russian).

Lyubimov, B. P. (2002). Geomorphological particularities of gully erosion in arid zone. Journal of Geomorphology, 2, 18 (in Russian).

Mairin, S. Ye., \& Sterkin, V. D. (1961). Geological map of USSR, scale 1:200000. Series Djungarskaya, sheet L-43-XXXVI. Moscow (in Russian).

Pendergrass, A. G., \& Knutti, R. (2018). The Uneven Nature of Daily Precipitation and its Change. Geophysical Research Letters, 45(21), 11980-11988. https://agupubs.onlinelibrary. wiley.com/doi/epdf/10.1029/2018GL080298

Vanmaercke, M., Poesen, J., Van Mele, B., Demuzere, M., Bruynseels, A., Golosov, V., Rodrigues Bezerra, J. F., Bolysov, S., Dvinskih, A., Frankl, A., Fuseina, Y., Teixeira Guerra, A. J., Haregeweyn, N., Ionita, I., Makanzu Imwangana, F., Moeyersons, J., Moshe, I., Nazari Samani, A., Niacsu, L., Nyssen, J., Otsuki, Y., Radoane, M., Rysin, I., Ryzhov, Y. V., \& Yermolaev, O. (2016). How fast do gully headcuts retreat? EarthScience Reviews, 154, 336-355. https://doi.org/10.1016/j.earscirev.2016.01.009

Veretennikova, M. V., Zorina, Ye. F., Kovalev, S. N., Lyubimov, B. P., Nikolskaya, I. I., \& Prokhorova, S. D. (1998). Modern gully erosion of the agricultural lands and forecast of its possible development. Erosive river-bed and river-mouth processes, 11, 103-111 (in Russian). 